\title{
Tu tem olhado, quebranto?
}

\section{A Medicina Popular no contexto urbano}

\author{
Maria Cecilia Dias de Miranda* \\ Marta Valéria Capacla*
}

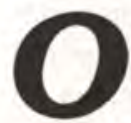

objetivo deste artigo ${ }^{1}$ é o de apresentar as principais características das práticas dos benzedores, situando esses agentes de cura enquanto especialistas da Medicina Popular, que combinam um saber tradicional a respeito dos cuidados com a saúde, com elementos da religiosidade popular.

As benzeduras consistem basicamente em gestos, rezas, simpatias, prescrição de ervas medicinais, remédios caseiros, imposição de mãos sobre a cabeça do benzido ou sobre as partes do corpo afetadas, com a finalidade de restabelecer o bom funcionamento do organismo ou eliminar influências espirituais negativas, causadas por mau-olhado, quebranto ou castigo de forças divinas.

Os benzedores distinguem-se pela capacidade da cura, porque conforme afirmam possuem um dom, uma capacidade dada por Deus de colocar a seu favor forças "mágicas" presentes na essência do universo. Em outros termos o benzedor serve também como intermediário na relação entre o individuo e o sagrado, podendo portanto suplicar a providência divina nos casos de doença e necessidade de proteção espiritual. $^{2}$

Para contextualizarmos as benzeduras no meio urbano, devemos verificar o espaço que essa prática ocupa no Sistema de Saúde. Podendo dividir esse sistema em dois subsistemas: - o não-institucionalizado (compreende a Medicina Popular, Medicina Alternativa ) e o subsistema institucionalizado (compreende a Medicina Oficial - aquela ensinada nas universidades e praticada nos hospitais e unidades básicas de saúde ). Será no subsistema não institucionalizado o lugar onde as benzeduras enquanto exemplo de Medicina Tradicional e Terapia Religiosa irão constituir seu campo de atuação e legitimidade.

A Antropologia hoje procura entender todas essas atividades como sendo práticas de saúde atualissimas, legitimas, extensamente praticadas no meio urbano e procuradas não apenas em razão do fator econômico e das dificuldades de acesso ao sistema oficial de saúde: os usuários escolhem seus itinerários terapêuticos principalmente em função de fatores culturais.

\section{Medicina Tadicional, Terapias Religiosas e Medicina Oficial}

Enquanto parte da Medicina Popular, podemos classificar as benzeduras entre as práticas da Medicina Tradicional e entre as Terapias Religiosas.

A Medicina Tradicional constitui-se num conjunto de conhecimentos a respeito da saúde, doença e cura, desenvolvidos pelo povo nas zonas rurais e transmitidos oralmente através das geraç̃̃es. Tem um caráter essencialmente prático, empírico, pois seus principais procedimentos ocorrem nas experiências com a utilização dos recursos naturais e culturais disponiveis. Tendo surgido nosprimeiros séculos da história do Brasil, combina elementos de origem indigena. africana e européia, com práticas mágicas e crenças do Catolicismo Popular.

Como processo de urbanização, e com a migração dos especialistas da Medicina Tradicional (curandeiros. benzedores, partciras, etc.) para as cidades, grande parte dessas técnicas mágicoempiricas foram esquecidas ou transformadas.

$\mathrm{O}$ aparecimento de novas doenças, o desenvolvimento da medicina universitária, a dificuldadedeacesso aos recursos da natureza utilizados nos rituais e a modificação do contexto cultural inviabilizaram a transmissão e o uso de grande parte dos conhecimentosmédicos tradicionais.

O sociólogo Florestan Fernandes já em 1941 realizou uma pesquisa em algumas áreas urbanizadas de
São Paulo sobre o "folclore mágico" - superstições, simpatias e benzeduras. Previa que os efeitos da secularização, isto é, a racionalização que a vida urbana impõe, transformariam essas práticas sem, entretanto, extingüi-las; ocorreria um reajustamento pelo qual sobreviveriam apenas as práticas mais adaptadas à vida urbana.

Atualmente a ação dos benzedores é circunscrita a um âmbito restrito. Curam doenças espirituais (mau-olhado, quebranto) e outras de menor gravidade (cobreiro, erisipela, engasgo, mau jeito, etc.). Os recursos mais utilizados são as rezas, ervas medicinais e simpatias. 
Será portanto nos vazios deixados pela Medicina Oficial que os agentes populares de cura irão conquistar sua clientela. Não sendo possível determinar clinicamente alguns males como o quebranto, o mau-olhado, o encosto, será nas Terapias Religiosas que o doente obterá a oportunidade de diagnóstico e tratamento. As religiões possibilitam que os indivíduos orientem suas percepções a respeito das doenças a partir de um ponto de vista mais abrangente, que transcende as causas físicas, recuperando noções miticas que fogem do âmbito dos modelos racionais propostos pela medicina científica. O estado de desordem provocado pela doença, o medo da morte, criam no paciente uma postura subjetiva que se abre para a fé e o irracional.(CAMARGO,1987)

\section{A Importância da Fé}

"- Então precisa a pessoa creditá em Deus, porque credita em Deus credita em tudo em tudo, né. Peguei e curei, graças a Deus. " (Seu Sebastião-benzedor).

Percebe-se entre os benzedores um uso distinto da fé, uma vez que a matriz religiosa envolvida é a do Catolicismo Popular. A religião, nesse caso é mobilizada para a resolução e superação das carências espirituais e materiais do cotidiano.

A fé enquanto capacidade de se acreditar antecipadamente num resultado que se deseja é elemento essencial para que as benzeduras tenham eficácia. Quando a comunidade reconhece o benzedor enquanto sujeito capaz de propiciar alívio aos infortúnios e às aflições através da utilização de forças sobrenaturais, cria-se uma disposição emocional e psicológica favorável à realização da cura e à manutenção da tradição das benzeduras.

\section{As Diferentes Definições de Doença}

As representações a respeito da doença são específicas a cada terapêutica da Medicina Popular. Assim, as Terapias Religiosas explicam as doenças em virtude do distanciamento entre individuo e sagrado, ou por sentimentos negativos, "mal feitos"' de outras pessoas. $\mathrm{Na}$ Umbanda por exemplo, o não cumprimento dos compromissos para com as entidades, as demandas e os encostos, entre outros, causam desordens na vida do fiel. Já o Pentecostalismo explica a doença por causa do pecado ou pela presença do demônio. No Catolicismo Popular, os benzedores, fazendo uso da Medicina Tradicional, atribuem as doenças à causas físicas (excesso de sol na cabeça, mau-jeito, quebra de resguardo, indigestão) ou a causas espirituais (a inveja no caso do Mau-Olhado e o excesso de amor no caso do Quebranto).

As explicações a respeito das doenças oferecidas pela Medicina Popular são fruto de um saber produzido pelo povo, e portanto espelham suas visões de mundo, ou seja, suas experiências, seus valores, suas crenças religiosas, seus conhecimentos a respeito da natureza e do funcionamento do organismo. Esse saber específico é ignorado pela Medicina Oficial porque é uma produção cultural popular, enão erudita; se constrói a partir de elementos religiosos, e não cientilicos e porque valoriza as condições subjetivas na determinação de doença e cura.

Alèm do mais, conforme Camargo, a tendência da Medicina Oficial é aumentar a cisão entre mente e corpo: "é a doença que assume uma entidade própria, quase separada do paciente e essa espécie de 'espirito desencarmado' que recebe a atenção do médico. Isolando-se a subjetividade do paciente, sobra o lado quantilicável e acessível à tecnologia como exames de laboratório, RX, etc.' (op.cit. p. 449)

\section{Os Caminhos da Cura}

Em busca da saúde o doente tem à sua disposição vários sistemas de cura: pode recorrer aos especialistas das Terapias Religiosas (pais e mães-de-santo, médiuns, pastores ou cooperadores, benzedores), aos da medicina tradicional (curandeiros, vendedores de ervas medicinais, e outros), das medicinas alternativas (cromoterapeutas, acupunturistas, massagistas, etc.) ou mesmo aos especialistas que utilizam com mais frequência o sistema institucional, como os farmacêuticos-práticos que indicam medicamentos,

A escolha será norteada pelo tipo de doença, pelas possibilidades de acesso aos serviços, e principalmente pelas visões de mundo do paciente, ou seja, as explicações a respeito de saúde, doença e cura e opções religiosas

No subsistema não institucionalizado de saúde o discurso do doente é valorizado pelo agente promovedor da cura. As explicações a respeito das doenças oferecidas são mais bem compreendidas e identificadas com o universo cultural do paciente.

\section{Três Benzedores em São Paulo...}

Quando nos propusemos à investigação da prática do benzimentona metrópole não imaginávamos, de fato, que a cidade abrigava um número tão grande de benzedores.

Por necessidade da pesquisa pudemos ter contato mais frequente com apenas três benzedores - D.Nininha, D. Joana, Seu Sebastião - moradores respectivamente dos bairros de Pirituba, São Miguel, e Vila Ema. São idosos, migrantes (do nordeste e do interior de São Paulo), muito procurados nos seus bairros, e não cobram pelo benzimento. Entre os rituais utilizados por eles há algumas variações, entretanto, a matriz religiosa comum é retirada do Catolicismo Popular.

Para cada tipo de doença existem rezas ${ }^{3}$ definidas que têm um poder em si e são acompanhadas pelo sinal da cruz. Em alguns casos são utilizados objetos domésticos (pratos, linha, tesoura, óleo, etc) e objetos sagrados (velas, imagens de santos, ramos de arruda, etc).

O benzedor age diretamente sobre a doença identificando os seus sintomas e definindo uma terapêtica especifica. No bucho virado, por exemplo, ele manipula o corpo do paciente

".(..) eu pego a criança pela perna do treis soco na barriga. Se é grande, eu pego ele aqui assim por trás e suspendo ele, e você vê que vai no lugar "'(Sr. Sebastião).

Um exemplo clássico de reza para curar mau-olhado, transmitido com pequenas variações é o seguinte:

"F ulano, tu temolfado, quebranto?

Com dois te Gotaram com três eu te tiro Comos poderes de Deus e da Virgem Maria

Se é no comer, se é no beber,

Se é na gordura, se é na magrem

Se é na feiura, se é na boniteza

Se é mau-olhado de pai, de miè,

De vizinfios, parentes, pessoa estranfia

Bucho virado, bicha assustada, dor de cabega Febre, dor de barriga.

Curai-o Senfior, com os poderes de Deus e da Virgem Maria

Fulano tu temolhado, quebranto

Com dois te Gotaram, com três eu te tiro

Comos poderes de Deus e da Virgem Maria

Vá pras ondas do Mar Sagrado 4

Aonde näo canta galo, nem galinfia, olfado, quebranto, a inveja,

e toda a perseguicaio que está com fulano de tal Comos poderes de Deus e da Virgem Maria. Pai, Filfo, Espirito Santo.

- Reza Tai Nosso e oferece ao dono dessa omacio."

(D. Ninintia e Sr, Joaquim-in memorian)

Devido à grande procura e ao sentimento de compromisso com seu dom, alguns benzedores reservam dias e horários especificos para o atendimento. - "Ai eu fiz uns cárculo, dei treis dias pra eles e fico com très dias pra mim. Eu benzo de segunda, quarta e sexta-feira, né ". (Seu Sebastião) 
O espaço de atendimento pode ser um local especial ou não. Seu Sebastião benze sempre em seu quarto onde mantém uma mesa com todos os objetos sagrados, além de imagens de santos nas paredes. D. Nininha, ao contrário, parece considerar que todo espaço é sagrado uma vez que realiza suas benzeduras até mesmo na rua, quando é abordada por seus clientes.

Os benzimentos também podem ocorrer à distância, por intermédio do nome do paciente ou de objetos de uso pessoal como roupas e remédios. A lógica que orienta essa possibilidade de manipulação de forças é a lógica do contato, isto é, um objeto pessoal substitui seu proprietário, podendo, desta forma, ser um veículo para atingi-lo. "Eu morava em Diamantina, e meu genro morava aqui. Então ele mandava carta là pra casa e o meu marido então lia a carta e falava: - Joana tem um benzimento aqui procè benzè de fulano de tal. Só ele me dava o nome, né. " (D. Joana)

O uso de medicamentos e ervas é específico para cada doença. Alguns exemplos de remédios segundo Seu Sebastião: "'treis pimenta do reino, põe num copo de água e toma " (para prisão de ventre); "então cozinha treis foia de comigo ninguém pode, e quatro foia de copo de leite" (para Erizipela).

Em muitos casos a relação entre a doença e oritual utilizadoé metafórica. No benzimento de lombriga, utilizam linha, tesoura e copo de água. Oritual inicia-se com uma reza, colocando em seguida a linha branca dentro do copo com água. A disposição das linhas na água corresponde à das lobrigas na barriga e o corte da linha representa a interrupção da ação das lombrigas.

\section{Conclusão}

A grande utilização do benzimento e outras formas de Medicina Tradicional pelas populações urbanas mostra que estas práticas têm sua razão de ser mesmo na sociedade moderna: a razão científica não dá conta de resolver todos os aspectos da vida. Contrastando com os altíssimos investimentos em tecnologias de ponta, as Políticas Públicas de Saúde ainda não resolveram os problemas básicos, como o controle de algumas epidemias e a má qualidade dos serviços prestados.

Um sistema mais global como a religião inclui em sua explicação de mundo elementos que a ciência ignora; contudo, não se deve impor nem substituir uma visão de mundo pela outra. Para a Medicina Oficial isso significa repensar a filosofia de sua prática, reconhecendo o individuo como um ser cultural, e não unicamente biológico.

- Maria C. Dias de Miranda e Marta Valéria Capacla são estudantes do Dpt de Ciências Sociais/USP.

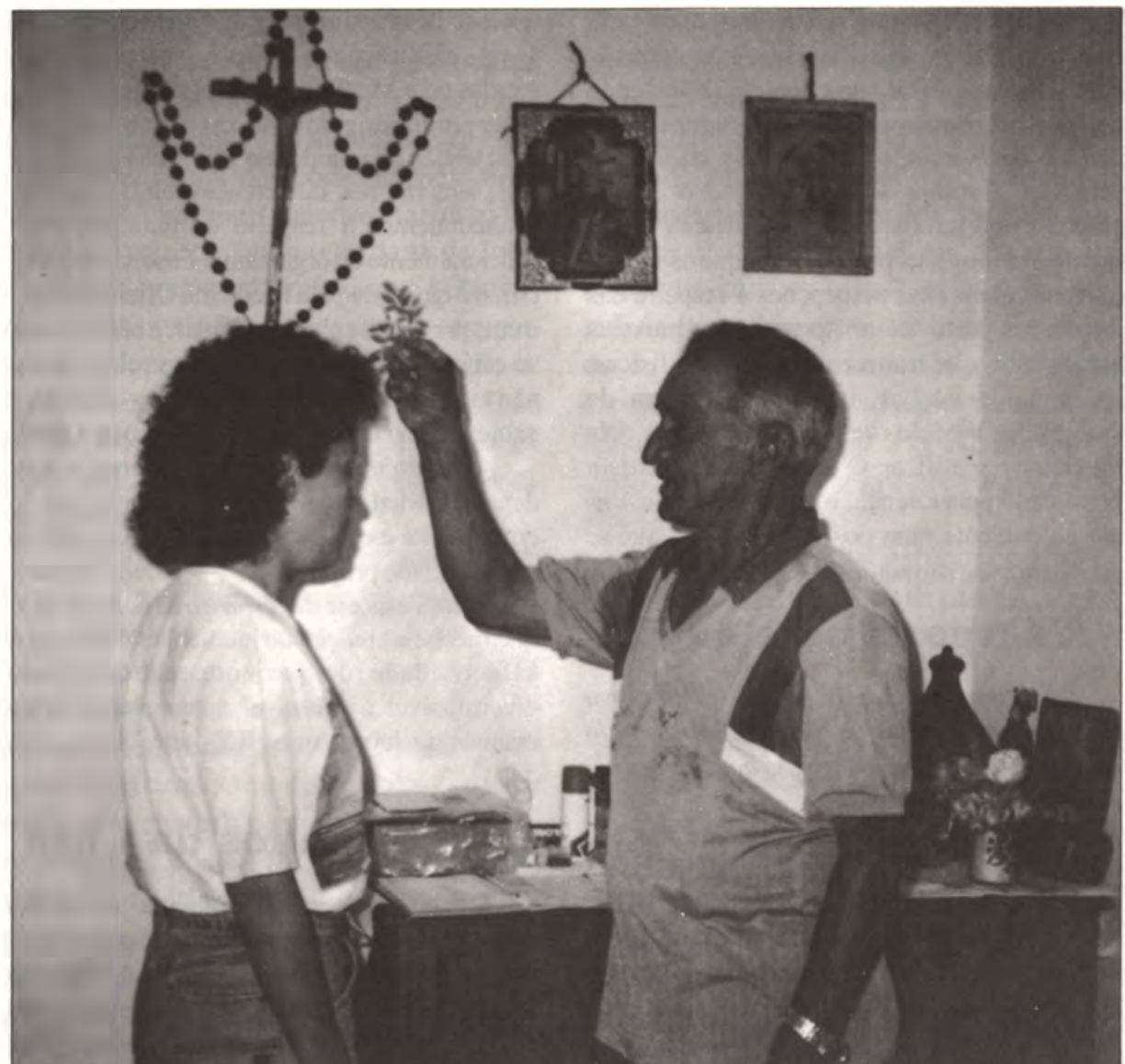

Foto: Marta Valéria Capacla

\section{NOTAS}

(1) Este artigo foi baseado no relatório de pesquisa "Medicina Popular: as Benzedeiras", realizado por Inès Rosa Bueno, Márcia Santos Irala, Maria Cecilia Dias de Miranda, Marta Valéria Capacla, Vanderli Maria da Silva e Vera Lúcia Bento. Foi desenvolvido para a disciplina Pesquisa de Campo em Antropologia ministrada pelo Prof Josè Guilherme Cantor Magnani no curso de Ciências Sociais da USP).

(2) "A benzedeira pode ser praticante de uma religiào (calólica, evangélica, kardecista, umbandista, exotérica ) (...)" (OLIVEIRA, 1983, p.114). Tralaremos aqui só daquelas de orientaçâo católica. Embora encontrem sua legitimidade na religiầ, a Igreja Católica nâo reconhece oficialmente sua prática. No seu frabalho de cura năo são agentes de conversão à Igreja e nem defendem a doutrina calólica

(3) No que se refere à transmissão dessas rezas alguns benzedores preferem conservá-las em segredo, ou ensinà-las em situaçóes apropriadas, como na Sexta-feira Santa ou pouco anles da sua morte. Ensinálas em situaçб̄es indevidas acarreta a perda do dom.

(4) "É para as ondas do mar salgado ou sagrado que os benzedores enviam os maus-olhados e invejas; 0 que não é desejado è endereçado para um lugar tão distante onde tambèm nâo se ouve o canto do galo. É o poder do sal capaz de quebrar todos os encantos e prender as doenças ou espiritos indesejâveis. "( ARAÚJO, p.117).

\section{REFERÊNCIAS BIBUOGRÁFICAS}

ARAÚJO, A M. - A Medicina Rústica - Săo Paulo. Nacional, $3^{2} \mathrm{ed} .1979$

BRANDĀO, C.R.- Memória do Sagrado - Săo Paulo. Paulinas, 1985.

CAMARGO,C.P.F.etalii - Terapias Religiosas em São Paulo - Relatório de Pesquisa, São Paulo, CEBRAP 1987.

FERNANDES, F - Folclore e Mudança Social em Săo Paulo - Sâo Paulo, Anhambi, 1961

LOYOLA, M. A.- Medicos e Curandeiros: Conflito Social e Saúde -São Paulo, Difel, 1984

MEZZOMO, T.M. - Entre o oficial e o legitimo: o subsistema nào institucional de atençâo à saúde em São Paulo - Dissertação de Mestrado , FGV.São Paulo, 1992.

MONTERO,P. - Da doença à desordem: A magia na Umbanda - Rio de Janeiro, Graal, 1985

OLIVEIRA, E.R. - O que è Benzeção - Sào Paulo,Brasiliense, 1985.

Paulo, Brasiliense, 1984

O que è Medicina Popular - Săo

"Doença, cura e benzedura." IN História: Questōes \& Debates. $n^{\circ} 4$, v.6, Curitiba 1983, pp.111-119

QUEIRÓZ, M.S. - Representaçōes sobre saủde e doença. Agentes de cura e Pacientes no contexto SUDS - Campinas, UNICAMP, 1991

- "Feitiço, mau-olhado e susto: seus tralamentos e prevençōes - Aldeia de Icapara" - IN Religiãoe Sociedade, n5, Rio de Janeiro, 1980, pp. 131 . 160. 